\title{
EDUCAÇÃO POPULAR SUPERIOR: RECRIAÇÃO DA MARCA DA EXCLUSÃO NO CAMPO EDUCACIONAL?
}

\section{Éducation populaire supérieure: recriação de la marque de l'cexclusion dans le domanine éducatif?}

Maria Emilia Bertino Algebaile ${ }^{1}$

\section{Resumo}

Neste trabalho, discutem-se algumas implicações contidas na expressão "educação popular superior", a partir da investigação sobre a expansão do ensino superior, no Brasil, ao mesmo tempo em que se procede ao resgate do conceito de educação popular. Concebendo a privatização do ensino superior no Brasil como uma política de Estado, a "desobrigação" estatal para com este nível de ensino passa a se concretizar em duas perspectivas: 1) transformando a educação pública em educação pública não-estatal e 2) estimulando o empresariamento do ensino. Falar em "educação popular superior" enseja a idéia de uma expansão da dualidade da educação brasileira para outros níveis de ensino, numa recriação da marca da exclusão dentro do campo educacional. O que seria uma possibilidade de inserção transformase num interdito, pois a própria estrutura dos cursos é montada de uma forma que, em última análise, impede a inserção não subalternizada desses novos "universitários" no mercado de trabalho. Diante disso, a expressão "educação popular superior" parece-nos surgir na contra-mão da perspectiva crítica de educação popular. A exclusão das camadas pobres continua a ser uma marca no campo educacional.

Palavras-chave: Privatização; Ensino superior; Exclusão; Educação popular.

\section{Résumé}

Dans ce travail, on discute quelques implications qui sont dans l' expression "éducation populaire supérieure", à partir de l' investigation sur l' expansion de l' enseignement supérieur, au Brésil, au même temps qu' on procède une nouvelle conceptualisation de l' expression éducation populaire. En

Professora da Universidade Federal Fluminense. Mestre em Educação (Universidade Federal Fluminense). Rua Gago Coutinho, 46 - Ap. 401 - Laranejiras - 22221-070 - Rio de Janeiro - RJ 
comprennant la privatisation de l' enseignement supérieur au Brésil comme une politique de l' Etat, la manque d' obligation étatique pour ce niveau d' enseignement passe par deux perspectives : 1) la transformation de l' éducation publique par l' éducation publique non-étatique et ; 2) l' estimation de rendre l' enseignement une entreprise. Quand on parle sur " l' éducation populaire supérieure ",ça nous donne l' idée d' un accroissement de la dualité de l' éducation brésilienne pour les autres niveaux d' enseignement, dans une re-création de la marque de l' exclusion dans le champ éducationnel. Ce qui était une possibilité d' insertion devient un chemin interdit, puisque la propre structure des courses est organisée d' une manière que, par dernière analyse, interdit l' insertion de ces nouveaux " universitaires " dans le marché du travail. De cette manière, l' expression "éducation populaire supérieure ", nous paraît commencer par le sens contraire de la perspective critique de l' éducation populaire. L' exclusion des couches pauvres continue à être une marque dans le champ éducationnel.

Mots-clé: Privatisation; Enseignement supérieur; Exclusion; Éducation populaire.

Este trabalho é um desdobramento de estudo mais amplo desenvolvido com o objetivo de determinar a especificidade e os determinantes da expansão do ensino superior no Brasil, considerando o processo de privatização das políticas sociais, em especial as políticas educacionais voltadas para o ensino em nível superior no Brasil nos anos de $1990^{2}$.

Entendendo a privatização do ensino superior uma política de Estado, considera-se como parâmetro de análise, no presente estudo, a expansão dos cursos de graduação, buscando perceber a distância entre as condições concretas de oferecimento desses cursos e as aspirações do alunado que se sente atraído (e traído) pela possibilidade de conquista de um (novo) patamar mínimo de educação. Para isso, torna-se importante compreender esta relação a partir de discussões que vêm se apresentando no campo educacional e que acabam por rotular determinado tipo de ensino superior, em instituições privadas deste nível de ensino, com a expressão "ensino popular superior"3.

Tomando a educação popular no Brasil, sua gênese, seus objetivos e sua especificidade, procura-se perceber em que sentido o termo "popular"

2 Pesquisa desenvolvida pelo Coletivo de Estudos sobre Política Educacional da UFF durante os anos de 2001 e 2002, apresentada em Neves, 2002.

3 Tal expressão não se configura de forma "oficial", ou seja, não se apresenta nos principais documentos de organismos como o MEC, a ABMES e mesmo nos organismos internacionais. Mas tem sido aplicada entre alguns profissionais do ensino superior, no Rio de Janeiro, na tentativa de "justificar" a baixa qualidade do ensino ministrado derivada do pouco preparo dos alunos advindos de um Ensino Médio deficiente. 
pode estar sendo apropriado como forma de legitimar um movimento que traz em si a negação do que até então se entende por uma educação popular.

Partindo da hipótese de que a graduação no Brasil vem se apresentando como forma de ampliação da dualidade observada no sistema educacional brasileiro, principalmente no que se refere ao ensino médio, pretende-se desvelar um discurso e uma prática que se apresentam como política de inclusão, mas que, na realidade, se manifestam de forma perversa, uma vez que contribuem para recriar, sob novos signos, a velha marca da exclusão no campo educacional brasileiro.

\section{A redefinição das políticas sociais e as políticas educacionais}

A implementação das políticas sociais, em especial, as políticas educacionais, nos anos de 1990, estruturam-se a partir de um novo modelo que, além de seguir o receituário dos organismos internacionais - financiadores dessas políticas - é também o resultado de debates entre os diversos atores sociais.

Inserida no campo das políticas sociais, é importante observar que a educação também não se apresenta de forma homogênea; é o resultado de embates entre capital e trabalho. Logo, é no contexto de redefinição destas políticas, nos anos de 1990, que se deve buscar os determinantes do redirecionamento da política educacional no Brasil. É, portanto, importante ressaltar que

marcado pelas transformações ocorridas no cenário internacional, o Brasil, nos anos de 1990, adota medidas para a reforma do aparelho do Estado, o que significa um redirecionamento da concepção de Estado e dos parâmetros de suas ações. Ao modelo de "Estado interventor" sucede um Estado que diminui suas funções no campo social e atribui à iniciativa privada as funções que eram de sua responsabilidade. Apesar deste aparente antiestatismo, esta proposta de reforma defende a manutenção de um Estado forte para garantir as condições adequadas à expansão do mercado e ao alívio da pobreza dos mais necessitados (ALGEBAILE, NASCIMENTO; SILVA, 2002, p. 94).

Seguindo preceitos da ideologia neoliberal, o modelo implementado no Brasil apresenta, entre outros aspectos, o corte nos gastos sociais. Tal medida abriu espaços para a iniciativa privada e para o que Boito Jr. (1999) chamou de "burguesia de serviços" ${ }^{4}$. Por outro lado, a diminuição dos gastos

4 O termo burguesia de serviços é usado por Boito Jr. (1999) para caracterizar a fração da burguesia que está relacionada à exploração dos serviços de saúde, educação e previdência privada, parte crescente dos serviços públicos que vêm sendo transformados em mercadoria. 
sociais conduziu à focalização das políticas sociais na questão da pobreza. A este respeito, merece destaque o fato de que

A focalização das políticas sociais na questão da pobreza pode ter um forte apelo político, mas não tem contemplado uma enorme parcela da sociedade. Há um claro privilégio do econômico em detrimento do social. Na área educacional, esta orientação se manifesta na forma de focalização dos gastos federais com o ensino fundamental e a redução, cada vez mais acentuada, de investimentos no ensino superior, que se torna um campo aberto aos investimentos privados. (ALGEBAILE, NASCIMENTO; SILVA, 2002, p. 102).

Aliada a isto, existe a construção da idéia de que a articulação entre educação e empregabilidade se coloca como ponto chave para trabalhadores de todas as áreas, recaindo sobre escolas, universidades e empresas a "responsabilidade" pela criação das condições necessárias a tal articulação.

As alterações preconizadas pela reforma educacional no Brasil redirecionam o papel da educação e da escola e, conseqüentemente, aliam a formação e a qualificação como elementos fundamentais ao processo de competitividade resultando, assim, em ações político-pedagógicas no âmbito dos currículos da educação formal e não-formal (CATANI, OLIVEIRA DOURADO, 2002, p. 72).

No Brasil, o primeiro governo do presidente Fernando Henrique Cardoso (1995-1998) teve como objetivo principal a abertura da economia. Esta meta foi cedendo lugar à reforma trabalhista visando à flexibilização do trabalho, em especial das garantias trabalhistas. O processo de reforma curricular não pode deixar de ser analisado a partir de sua inclusão no bojo dessas reformas; ao contrário, "é exatamente nesse contexto que devemos entender o processo de reforma curricular, em curso, que objetiva a flexibilização da formação nos cursos de graduação para uma adaptação permanente a cada nova realidade do mercado." (CATANI; OLIVEIRA; DOURADO, 2002, p. 78, grifo nosso).

Outro aspecto a ser ressaltado diz respeito à mercantilização do ensino superior, cada vez mais crescente. Com a nova configuração das políticas sociais, para usar uma expressão de Lima (2002), o capital parte "em busca de novos campos de exploração".

Nos últimos anos, elementos de continuidade e novas expressões vêm à tona no que tange ao processo de abertura do setor educacional como opção de investimentos de grupos privados. O elemento de continuidade é garantido pelo reforço à concepção de educação como instrumento de preparação de 
mão-de-obra para o mercado e também de dominação ideológica através da visão de mundo empresarial. O elemento de novidade é o crescente empresariamento da educação com três aspectos importantes. O primeiro diz respeito à globalização crescente dos sistemas educacionais na América Latina, sendo cada vez mais significativos os incentivos para que universidades públicas e privadas associem-se às universidades globais (...). O segundo aspecto refere-se à constituição de universidades corporativas implementadas nas ou pelas empresas. O terceiro se expressa no incentivo ao investimento na educação à distância, impulsionada pelo desenvolvimento das inovações tecnológicas. (LIMA, 2002, p. 54, grifos nossos).

Assim é que, observando os novos contornos assumidos pela educação superior, pode-se captar uma tendência ao cumprimento de algumas metas de organismos internacionais que foram incorporadas pelo MEC sendo implementadas, principalmente, por faculdades privadas.

\section{Ensino Superior no Brasil nos anos de 1990}

O processo de reconfiguração da educação superior brasileira apresenta, entre outros aspectos a serem investigados, a ampliação de vagas para este nível de ensino por meio da expansão das instituições privadas, assim como o desenvolvimento de uma nova política de currículo para a graduação. Considerando o processo de reestruturação produtiva do capitalismo global, estabelecem-se, de forma polêmica, relações entre a questão da formação e da produção do conhecimento e da formação profissional e tais discussões vão estar embasadas pelos embates históricos entre capital e trabalho. Tais debates trazem em seus desdobramentos de ordem prática a necessidade de desvelamento sobre as relações estabelecidas entre a escola e a empresa, pois, na "ótica empresarial, verifica-se que grande parte das vantagens está associada à qualificação dos recursos humanos e à qualidade dos conhecimentos produzidos" (CATANI; OLIVEIRA; DOURADO, 2001, p. 69).

Partindo da perspectiva de que a ampliação da oferta de vagas para o nível de ensino em questão não é garantia de inserção das camadas pobres da sociedade, tanto no campo educacional, como no mercado de trabalho, vamos desenvolver nossa análise.

Em recente trabalho de pesquisa ${ }^{5}$, a privatização do ensino superior no Brasil é apontada como uma política de Estado e não, simplesmente, como parece à primeira leitura, um movimento do mercado.

5 A este respeito, consultar Neves, 2002. 
Analisando o Plano Diretor da Reforma do Aparelho do Estado ${ }^{6}$, destacamos que

a redefinição das funções do Estado cria uma nova estrutura administrativa para a aparelhagem estatal. Na área educacional, determina a responsabilidade do Estado em subsidiar a Educação Básica, apresentada como atividade exclusiva de Estado, abrindo à possibilidade de privatização do ensino superior - serviço não-exclusivo do Estado - através de medidas como a atuação do Estado simultaneamente com outras instituições públicas nãoestatais e privadas, de acordo com o Plano Diretor de Reforma do Aparelho de Estado, 1995 (ALGEBAILEA, NASCIMENTO; SILVA, 2002).

Desta forma, a "desobrigação" estatal para com o ensino superior passa a se concretizar pelo incremento à privatização de duas formas distintas e concomitantes: 1) transformação da educação pública em educação pública não-estatal e 2) estímulo ao empresariamento do ensino.(NEVES, 2002).

Considerando, ainda, o caráter dual que a educação brasileira vem assumindo, há décadas, principalmente no que diz respeito ao ensino médio, quando se tem um tipo de ensino propedêutico (oferecido em sua maioria por instituições privadas com o objetivo de formar para a continuidade dos estudos em nível superior) e outro de profissionalização mais imediata (geralmente para as camadas pobres da população, que necessitam ingressar no mercado de trabalho), falar numa educação popular superior parece-nos uma ampliação desta dualidade, agora também enraizada no ensino superior. Segundo Neves (2000),

6 A reforma da aparelhagem estatal é implementada pelo Estado a partir de 1995, através do Plano Diretor da Reforma do Aparelho do Estado, indicando quais as atividades de que o Estado deve encarregar-se diretamente, aquelas que deve apenas coordenar e/ou supervisionar e quais as que deve entregar à iniciativa privada. O Plano propôs que o Estado neoliberal fosse composto de quatro setores: 1) núcleo estratégico, responsável pela definição de leis e políticas públicas e cobrança do seu cumprimento, formado pelos poderes Legislativo e Judiciário, pelo Ministério Público e, no Poder Executivo, pelo Presidente da República, ministros e seus auxiliares diretos; 2) atividades exclusivas, compreendendo serviços em que se exerce o poder extroverso do Estado - o poder de regulamentar, fiscalizar, fomentar. Entre as atividades exclusivas encontram-se o subsídio à educação básica, à previdência social básica, à compra de serviços de saúde pelo Estado, o controle do meio ambiente; 3) serviços não-exclusivos, correspondendo ao setor onde o Estado atua simultaneamente com outras organizações públicas não-estatais e privadas. As instituições desse setor não possuem o poder de Estado, mas este está presente porque os serviços envolvem direitos humanos fundamentais, como a educação e a saúde; 4) produção de bens e serviços para o mercado. Corresponde à área de atuação das empresas estatais, que tendem a posterior privatização. 
embora formalmente não seja impedido o ingresso de nenhum concluinte do ensino médio ao ensino superior, na prática, a organização dual do currículo reestabelece, no final do século, a histórica separação entre escola para pobre e escola para rico. Aliás, essa nova dualidade educacional é claramente expressa na proposta governamental de Plano Nacional de Educação para o nível médio de ensino. (...) A antiga dualidade (ensino médio e ensino técnico de nível médio) é superada pela extinção dos cursos técnicos de nível médio (p. 185).

A expansão do ensino superior, via privatização, passou a atrair um tipo clientela marcada pelo pertencimento às camadas mais pobres da população, em sua maioria oriunda de escolas de ensino médio públicas (regular ou supletivo) e trabalhadores em busca de maior "qualificação" e/ou alguma certificação.

Em vigor desde 1997, a proposta de educação profissional apresentada no Governo FHC se apresenta de forma seletiva, uma vez que tal modalidade de ensino se dá de maneira compensatória à escolarização dos trabalhadores. Tal proposta

repõe, atualizando, o dualismo real das trajetórias educacionais: para as massas trabalhadoras uma terminalidade precoce, assegurada pela educação profissional de nível técnico; para os egressos do ensino médio propedêutico, a possibilidade mais concreta de acesso ao nível superior de ensino, quer aos vários tipos de educação superior de natureza científica (universidades, centros universitários, faculdades integradas, faculdades e institutos superiores ou escolas superiores), quer aos de natureza tecnológica, realizados nos CEFETS, embora formalmente o acesso ao nível superior de ensino seja assegurado a todos que o desejarem. Além disso, essa terminalidade precoce é determinada, concomitantemente, pela acelerada privatização do nível superior de ensino e pelos salários aviltantes dessa parcela da força de trabalho. (NEVES, 2000, p. 199, grifos da autora)

Embora de grande abrangência, a "ampliação" da oferta do nível superior de ensino não se reflete no aumento da qualidade do ensino ministrado, antes, deve-se atentar para o fato de que tal movimento de expansão deve-se muito à implementação dos cursos seqüenciais ${ }^{7}$ de curta duração (dois anos), principalmente na área humana e de ciências sociais aplicadas. Uma vez que não necessitam de laboratórios e infra-estrutura sofisticada, a redução do tempo de formação permite o oferecimento de um preço mais baixo em relação aos cursos tradicionais. Aliando o baixo valor das mensalida-

\footnotetext{
7 Os cursos seqüenciais foram criados em 1996 pela Lei de Diretrizes e Bases (LDB), inspirados em experiências internacionais, como a França, objetivando ser uma alternativa para aqueles alunos que não podem fazer um curso de graduação plena, aligeirando sua formação.
} 
des ao tempo mais restrito para uma formação cuja certificação declarada é de nível superior, há um aumento de procura desses cursos, o que permite um aumento da receita das instituições que os oferecem.

Este "aligeiramento" na formação do trabalhador, recomendado pelos organismos internacionais e com o aval do MEC, vem atraindo um grande número de pessoas que estavam afastadas da escola há algum tempo, após o término do Ensino Médio. Assim como, nos idos de 1970, houve um "boom" dos cursos supletivos como forma rápida de diplomação (para o $1 .^{\circ}$ e o $2 .^{\circ}$ graus), nos anos de 1990 registra-se uma grande afluência de alunos em busca da diplomação em nível superior. Observa-se que a expansão da oferta do ensino superior dá-se não só em termos de ampliação das vagas, mas também em termos de uma diversificação de cursos que permitem encampar camadas da população que estariam excluídas da educação superior tradicional, devido à falta de tempo, recursos financeiros ou preparo para enfrentar um concurso vestibular em igualdade de condições com outros alunos advindos de um ensino médio de qualidade (incluindo-se, neste caso, escolas privadas e públicas como, por exemplo, os Cursos de Aplicação das Universidades Federais e Estaduais). Assim, tem-se uma educação superior mais rápida e mais barata para os que dela necessitam, ou seja, os mais pobres.

Esta forma de expansão do ensino superior não contribui com o desenvolvimento de práticas de conscientização e organização social o que, em última análise, impede a inserção desses novos "universitários" no mercado de trabalho de forma não subalternizada. Logo, a expressão "educação popular superior" parece-nos ter surgido na contra-mão da concepção histórica de educação popular.

\section{Contextualizando a educação popular}

A expressão "educação popular", no Brasil, surge pelos idos de 1930, aparecendo na formulação de políticas educacionais voltadas para a necessidade de extensão da escola primária para as crianças das camadas médias e das camadas populares ${ }^{8}$. Os debates e as práticas educacionais em torno de uma educação popular, no Brasil, ganharam força na década de 1960, com Paulo Freire.

Na luta contra um regime totalitário, a educação popular surgia como ação política,

8 As referências fundamentais sobre este tema são encontradas nos livros clássicos de Fernando de Azevedo, Lourenço Filho, Anísio Teixeira, Paschoal Lemme, entre outros. 
uma forma aguerrida de pensar uma experiência alternativa de fórum revolucionário contra todo um estado capitalista ditatorial. Hoje em dia, as coisas mudaram, mas não tanto. As ditaduras não são mais dos militares, mas das empresas. Talvez pese sobre nós uma ameaça internacional nessa nova ordem muito mais terrível, que é a ameaça deste poder que nem é globalizado e hegemônico, já é um poder imperial. Trata-se da construção de um Império de poder cuja sede é os EUA. Uma das traduções desta imperialização da educação dentro de um projeto de serviço direto ao capital é não apenas a privatização da educação. Países muito avançados possuem tanto escolas públicas, como escolas privadas, porém essas últimas, de fórum comunitário. Ou seja, elas estariam mais na construção de um terceiro setor, do que na vertente de um empresariado dominante da educação. A contrapelo disso, o que ocorre em todo o mundo é um processo que é pior do que a privatização (que é uma medida apenas intermediária), que é de mercantilização direta da educação.(BRANDÃO, 2003).

O processo de mercantilização da educação conduz à recriação da natureza da educação, que se transforma, de direito inscrito na Constituição Federal de 1988, em simples venda de serviços. Assim sendo, se a educação superior deixa de ser da competência do Estado, passando à esfera do Capital, a exploração do "serviço" educação caberá ao empresário possuidor do capital necessário para o investimento na área, bem como das condições concretas para o sucesso de seu "empreendimento".

Em que pese o contexto histórico e político do início das discussões sobre educação popular, no Brasil, sem dúvida, trata-se de tema atual, pois, embora sendo recriada ao longo do tempo, mantém sua característica emancipatória e é neste sentido que deve ser analisada. Uma questão que Brandão apresenta e que deve permear toda a nossa discussão acerca da educação popular é a seguinte:

O que é hoje uma educação popular emancipatória? A resposta eu não tenho, infelizmente. Mas posso levantar alguns pontos fundamentais como: a vocação de uma educação suprapartidária ou apartidária, que não se subordine a um projeto dominante hegemônico; a experiência da educação como prática de resistência; a convicção de que a educação não lida com o ajustamento de pessoas ao mundo social estabelecido, mas lida com a criação de pessoas inconformadas, capazes de se lançar na tarefa de criarem seu próprio mundo social (BRANDÃO, 2003)

A educação popular esteve historicamente relacionada aos movimentos populares. No Brasil, desde a década de 60, "a educação popular refere-se a uma gama ampla de atividades educacionais cujo objetivo é estimular a parti- 
cipação política de grupos sociais subalternos na transformação das condições opressivas de sua existência social" (SILVA, 2000, p.48).

Logo, reconhecendo a vocação emancipatória da educação popular como aquela capaz de formar pessoas para operarem transformações, um primeiro impasse se coloca ao analisarmos a expressão "educação popular superior", qual seja: estaria o termo "popular" mantendo seu significado histórico ou, na falta de outro melhor, estaria servindo apenas para explicitar a origem de classe da maioria do alunado do ensino superior das instituições privadas? Neste caso, a expressão "educação popular superior", estaria, de forma pejorativa, servindo de rótulo a um tipo de ensino "menor", que buscasse dar conta das inúmeras falhas e faltas apresentadas pelos alunos no que diz respeito ao conhecimento acumulado, aos conteúdos programáticos não apreendidos na Educação Básica, em especial, durante o Ensino Médio.

A questão que se coloca é a seguinte: o termo "popular" estaria aqui relacionado a um tipo de ensino de qualidade inferior? Dirigindo o olhar para um aspecto da educação popular que sugere um tipo de educação complementar - e tanto os movimentos de alfabetização de adultos (MOVA) como a educação de jovens e adultos (EJA) seriam exemplos disso - e reconhecendo que, do ponto de vista da elite intelectual brasileira, e mesmo do senso comum, existe a tendência a considerar as classes populares como portadoras de muitas lacunas e falhas que devem ser reconhecidas e corrigidas, o sentido de popular estaria relacionado a uma possível "escassez" de qualidade do ensino? Admitir isso seria o mesmo que reconhecer que, para uma classe vista como inferior, oferece-se uma educação igualmente inferior.

Brandão (2002, p. 117) lembra que "mesmo sendo historicamente uma criação mais da margem civil e contestatória do que da margem pública e consagradora do caminho por onde flui a vida social, o destino de uma educação de vocação popular é vir a tornar-se pública". Cabe salientar que, no caso em estudo, a "educação popular superior", do ponto de vista tanto de sua construção como de sua oferta, não está inserida no âmbito público. Ela não surge a partir de um movimento popular, nem é ofertada pela rede pública de ensino superior, embora esteja localizada na esfera da sociedade civil, porém, no âmbito do privado.

Deslocada da esfera estatal/pública para a esfera privada, a "educação popular superior" relaciona-se ao capital, sendo, portanto, portadora de valores e de uma concepção de mundo influenciada pela ótica do capital, num movimento contrário ao que apresenta a educação popular, articulada com práticas de enfrentamento e transformação social. Tal deslocamento, do âmbito público para o âmbito privado, realiza a tarefa de construção de um novo tipo de homem, (con)formando o alunado de acordo com o modelo capitalista em sua fase atual no Brasil. 
Logo, o uso do termo popular pode estar sendo utilizado - conscientemente ou não - como encobridor de práticas implementadas a partir de uma política de governo que privilegia as elites políticas a serviço das elites empresariais. É importante lembrar novamente Brandão (2002) quando afirma que "neste contexto de relações entre o poder e a cultura, a Educação Popular deveria ser conduzida civil e politicamente para o âmbito de um poder democrático de estado, para fazer-se ser, então, pensada e exercida como um direito de todos". (BRANDÃO, 2002, p. 117).

\section{Qualidade do ensino e classe social: alguns dados para reflexão}

Mensurar a qualidade do ensino superior é tarefa que pressupõe inúmeros e profundos estudos de vários matizes, o que, para o presente trabalho, seria impossível realizar. Neste breve estudo, considera-se a escola pública e a escola privada como referência para analisar alguns indicadores, a partir de dados estatísticos do IBGE, MEC e INEP, que possam contribuir para a fundamentação das discussões aqui apresentadas ${ }^{9}$.

Antes de tudo, quando se fala em expansão do ensino superior, é preciso ter claro que o universo a que se refere é, ainda, muito restrito. Para se ter uma idéia, no ano de 2001, as matrículas computadas neste nível de ensino correspondem a 5,38 \% do número total de alunos no Brasil $(56.299 .908)^{10}$. Indicadores de 2001 da FAPESP ${ }^{11}$ apontam que

o ensino superior no Brasil ainda continua tendendo a um pequeno porcentual da população escolarizável. As matrículas correspondem a apenas 10,4\% da faixa de pessoas entre 18 e 24 anos, em todo o país, e a 14,7\%, no estado de São Paulo. Nas várias regiões brasileiras há grande diversidade de cobertura, a mais baixa de todas verificando-se no Nordeste, com uma taxa de 5,1\%.

9 É importante lembrar uma questão que se coloca neste campo de análise: a possibilidade de manipulação dos dados divulgados, uma vez que as categorias consideradas não são sempre as mesmas nas sinopses apresentadas. Torna-se extremamente difícil comparar dados se não se tem uma seqüência; as condições de comparabilidade podem comprometer toda a análise. Mesmo atentando para esta possibilidade, no entanto, os dados divulgados apontam na mesma direção, o que reveste de maior confiabilidade os resultados das análises apresentadas.

${ }^{10}$ Consideramos os dados apresentados pelo INEP - Grandes Números da Educação Básica e da Educação Superior - 2001 (Pré-Escola, Classe de alfabetização, Ensino Fundamental, Ensino Médio, Educação Especial, Educação de Jovens e Adultos e Ensino Superior).

${ }^{11}$ Indicadores de Ciência, Tecnologia e Inovação em São Paulo - 2001. Capítulo 3 - Educação Superior: Graduação e Pós-Graduação. (http://www.fapesp.br/indct/cap03/cap03.pdf. Acesso em 24/04/2003. 
O GRÁFICO 1 mostra a desproporcionalidade existente entre o número total de matrículas registradas no Brasil, no ano de 2002, e o número de alunos do nível superior de ensino. Do total apresentado, apenas 5,97\% dos alunos se encontra no nível superior.

GRÁFICO 1 - RELAÇÃO ENTRE O NÚMERO TOTAL DE ALUNOS MATRICULADOS NO BRASIL E ALUNOS MATRICULADOS NO ENSINO SUPERIOR -2002

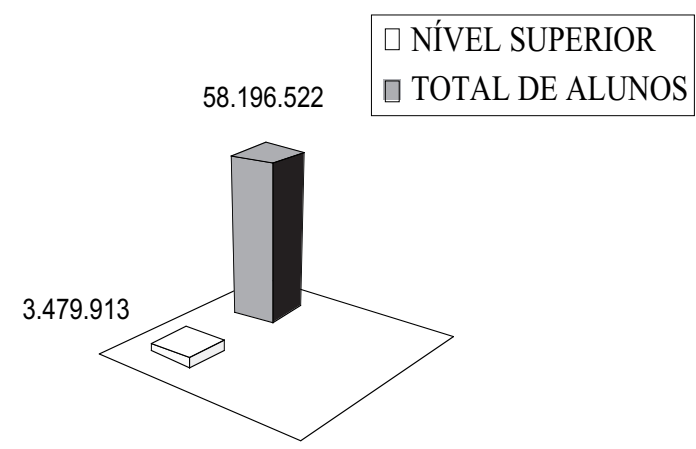

Fonte:MEC/INEP/2002

O universo dos que têm acesso ao ensino em nível superior, no Brasil, ainda é muito restrito. E entendemos que a responsabilidade pela universalização do ensino, em todos os níveis, é tarefa que só o Estado tem condições de realizar, uma vez que a iniciativa privada, instituição estruturada sob na ótica do capital, tem como objetivo final o lucro e não a diminuição da desigualdade social.

Levantamentos realizados pelo MEC/IPEA apontam que, de um total de 1.637 instituições de ensino superior, 195 IES são públicas, sendo 73 pertencentes à rede federal, 65 à rede estadual e 57 à rede municipal; enquanto que 1.442 pertencem à rede privada de ensino superior. Tais dados nos permitem conduzir o raciocínio analítico no sentido de que a expansão do ensino superior passou a ser promovida pela iniciativa privada ${ }^{12}$.

Considerando ainda os dados referentes às matrículas ${ }^{13}$, temos, no ano de 2002, de um total de 3.479.913 de alunos matriculados no ensino

12 Censo 2002. Sinopse da Educação Superior. MEC. www.inep.gov.br/superior/censosuperior/ sinopse/ Acesso em 21 de outubro de 2003.

13 Dados do MEC/INEP. Grandes Números da Educação Superior - Graduação - 2001. www.inep.gov.br Acesso em 18/03/2003. 
superior, uma concentração imensa na rede privada de ensino da ordem de 2.428.258, enquanto que a rede pública contou com 531.634 alunos matriculados em instituições públicas federais, 415.569 nas estaduais e 104.452 nas municipais, o que vem ratificar a tese de que houve realmente uma expansão via privatização da educação.

Não se contesta a importância da ampliação do número de vagas como fator fundamental para a democratização do ensino superior; no entanto, este aumento, por si só, não é garantidor de um aumento proporcional do acesso de estudantes de famílias mais pobres ao ensino superior, o que caracteriza a falta de uma política ampla que tenha como objetivo a inclusão da população de baixa renda no ensino superior em condições mais vantajosas que as atuais..$^{14}$

Dados do MEC sobre os cursos oferecidos por IES, indicam o movimento de expansão dos cursos de curta duração e seqüenciais. Em 2000 eram 178; em 2002 este número passou para 656, sendo que as instituições privadas respondem por cerca de $70 \%$ deste total.

Igualmente pode-se observar a disparidade entre instituições públicas e privadas no tocante ao número de concluintes dos cursos de graduação. De um total de 466.260 concluintes, no ano de 2002, nota-se que 315.159 são oriundos da rede privada de ensino superior. No entanto, analisando proporcionalmente os dados apresentados, percebe-se maior proporcionalidade dos alunos concluintes nas instituições públicas do que nas privadas.

Tomando como referência os dados de matrícula e número de IES nos anos de 1995, 1999, 2001 e 2002 ${ }^{15}$, observa-se que, na medida em que aumentam as matrículas no ensino superior nas instituições públicas (de 367.531 em 1995 para 1.051.655 em 2002), não existe um aumento proporcional do número de IES públicas (de 210 em 1995 para 183 em 2001 e 195 em 2002), o que pode indicar não somente a "retração" do estado neste nível de ensino, corroborando a tese de que a expansão do ensino superior, via privatização, se deu também pro meio de um "inchamento" das turmas, o que faz crer na

14 A "vantagem" aqui referida relaciona-se à melhoria da qualidade do ensino na educação básica e à ampliação do número de vagas nas IES, pois o que se observa é que, além das vagas reduzidas, estas são preenchidas em sua maioria por alunos oriundos de escolas privadas de nível médio. Não consideramos aqui as políticas ditas afirmativas, as políticas de cotas, uma vez que não dão conta de resolver o problema crônico da má qualidade do ensino ministrado no nível médio, o que acaba por maquiar uma situação, pois os alunos mais bem preparados terão condições melhores não só de ingressar, mas de acompanhar e ter um bom aproveitamento nos cursos do ensino superior.

15 Estes anos foram escolhidos como referência por representarem o início do período neoliberal (1995), o período do segundo governo FHC (1999/2001) e o último censo (2002). 
diminuição da qualidade do ensino. Observa-se um pequeno aumento referente ao ano de 2002, que não chega, no entanto, ao número de instituições de 1995.

Outro dado importante a observar é o crescimento das IES privadas, de 684 em 1995 para 1.442 em 2002, aliado ao crescimento substancial do número de matrículas (de 774.697, em 1995 para 2.091.529 em 2001 e 2.428.258 em 2002). Importa observar o aumento das IES privadas e de matrículas de 2001 para 2002.

No entanto, esses grandes números embotam uma visão do real. Tal expansão se dá de forma residual, ela é impactante não só pela grandiosidade de seus números, mas, e principalmente, se for considerada a relação entre a população escolarizável e o percentual representativo do ensino superior dentro deste universo. Tais dados apresentam um fosso gigantesco que não pode ser ignorado.

Importa, também, perceber que a expansão do ensino superior, via ampliação da rede privada de ensino, apresenta um desnível em relação às IES públicas, no que tange à relação entre o número de matrículas e o de professores no ensino superior. No ano de 2002, enquanto as IES públicas apresentam uma proporção de 11,40 alunos para cada professor em exercício, as IES privadas possuem 16,16 alunos por docente.

Não é difícil inferir que a disparidade entre IES públicas e privadas se intensifica ao se abordarem dados comparativos entre as diversas regiões do Brasil. Se os investimentos sociais realizados pelo estado obedecem a uma "certa lógica" excludente, em que as regiões Sul e Sudeste são priorizadas, de forma geral, por outro lado, os empresários ligados a todos os ramos de atividades realizam seus investimentos com base na perspectiva de alcançar o maior lucro. O quadro da educação superior, no Brasil, não se distancia destes dois aspectos. É no nicho deixado pela ausência de ação pública que o capital vai se estruturar de maneira bastante acentuada.

No Brasil, em termos percentuais, as instituições de ensino superior privadas representam a esmagadora maioria. Mas existem algumas especificidades que se tornam aparentes quando se passa a analisar os números referentes ao quantitativo de funções docentes nas IES, por região. Dados do MEC/INEP apontam que, nas Regiões Sudeste, Sul e Centro-Oeste tem-se um percentual acima dos $60 \%$ de profissionais nas IES privadas, enquanto que nas regiões Norte e Nordeste este percentual cai para a casa dos 37,88\% na média. Analisando tais dados, pode-se inferir que a ampliação do número de IES privadas não foi acompanhada do aumento proporcional do número de funções docentes, conforme já se havia observado anteriormente, no tocante à proporção professor/aluno; ou seja, a expansão das IES, via privatização, além de não se dar de forma ampla para todo o território nacional (destruindo o 
argumento de que o público é ineficiente e inoperante enquanto que o privado conseguiria dar conta das necessidades da população), ainda apresenta uma ampliação do número de alunos nas salas de aula, principalmente nas regiões brasileiras mais pobres, indicando a probabilidade de aumento nos lucros das IES privadas ${ }^{16}$.

Com salas superlotadas, professores sobrecarregados, alunos com pouca base em decorrência de um ensino médio de baixa qualidade, além de outros fatores de ordem econômica, cultural e social, colaboram para que a educação superior, em determinadas IES, esteja aquém dos parâmetros necessários à inclusão plena ${ }^{17}$ de seus alunos no mundo do trabalho. Daí, talvez venha tomando o conceito de uma "educação popular superior", como um tipo de educação próprio para dar conta de uma realidade que foge a uma visão mais crítica sobre o papel da universidade para o desenvolvimento do país e sua afirmação num mundo "globalizado".

Recriando a marca da exclusão

"A utopia não é o irrealizável, ela é apenas o ainda não-realizado".

Carlos Rodrigues Brandão (2003)

Ao identificar os determinantes da expansão do ensino superior no Brasil inseridos no contexto da privatização das políticas sociais, duas questões se apresentam intimamente relacionadas: a quantidade e a qualidade. É inegável o aumento do número de IES nos anos de 1990, da mesma forma que não se pode deixar de observar que tal expansão não foi acompanhada do aumento da qualidade necessária a uma formação consistente (e consciente) dos alunos das IES brasileiras.

Em busca de uma (nova) forma de inclusão social, observa-se que alunos oriundos das classes sociais mais baixas servem-se do ensino privado e, em especial, dos cursos seqüenciais, como talvez o único caminho para alcançar um patamar mínimo de educação que lhes permita escapulir da exclusão social, visando a ascender social e financeiramente via aquisição de conhecimentos técnicos.

${ }^{16}$ Em muitas cidades brasileiras o espaço utilizado pelas IES privadas são espaços públicos, cedidos por meio de convênios entre as prefeituras locais e as instituições de ensino. Além disso, há que se considerar que, se o número de alunos, por professor, aumenta, e se o salário deste mesmo profissional não sofre alteração, existe um aumento nos lucros auferidos pela IES, para citar apenas os aspectos mais concretamente observáveis.

17 Consideramos como inclusão plena a possibilidade de concorrência entre os alunos em condições as mais igualitárias possíveis, considerando o critério da competência como um dos atributos para a construção da necessária competitividade do mundo do trabalho no molde capitalista do neoliberalismo. 
As discussões travadas sobre o desnivelamento do ensino superior apontam para a necessidade de se repensar sua importância no cenário nacional. A natureza da educação pública deve ser única para todos os níveis de ensino. Coggiola e Helene (2002) alertam que "O que se deve expandir é o ensino superior público, gratuito, laico, de qualidade, socialmente referenciado, ou seja, integral. Essa é a única expansão universitária que abre uma perspectiva para a nossa e as futuras gerações".

Longe de se construir novos caminhos que possam garantir a inserção no mercado de trabalho atual de forma autônoma e não subalternizada, agregar ao ensino superior a qualificação de "popular" é construir um rótulo que encobre uma forma de recriar o velho signo da exclusão social, tão íntimo e perverso quanto real e velado. Tomando a educação popular no Brasil, sua gênese, seus objetivos e sua especificidade, percebe-se que o sentido do termo "popular" pode estar sendo apropriado como forma de legitimar um movimento que traz em si a negação do que até então se entendia por uma educação popular. Por outro lado, entendendo-se o ensino superior como etapa importante na construção de conhecimento, o "ensino popular superior" acaba por se caracterizar como um nível de ensino inferior ao patamar necessário para que se possa vir a falar verdadeiramente em inclusão social.

Os dados aqui apresentados nos permitem inferir que a "expansão" do ensino superior se deu de forma contundente no que se refere às IES privadas, mantendo e, em alguns casos, diminuindo a participação do setor público referente a este nível de ensino. É igualmente importante observar que, segundo dados da $\mathrm{Pnad} / 2003$, a educação exerce um impacto bastante lento sobre a desigualdade social. Embora se reconheça que houve um aumento significativo da escolaridade dos trabalhadores nos últimos 10 anos, este não foi acompanhado pelo correspondente aumento salarial. A "recompensa" pelo aumento da escolaridade veio, de forma bastante reduzida, para os que possuem nível superior. Isto, talvez, tenha impulsionado a busca das camadas populares pelos cursos deste nível de ensino. Ainda, segundo dados da Pnad/2003, considerando os trabalhadores com mais de 11 anos de estudo, em 1992, 27,5\% recebiam até dois salários mínimos, enquanto que este percentual, em 2002, sobe para 33\%.

Cumpre ainda ressaltar que a simples certificação não constitui elemento único para a inclusão no mercado de trabalho. Com as mudanças implementadas para a educação profissional no Brasil, nos últimos anos, o diploma passa a ter um valor relativo. O que vai conferir ao trabalhador um "maior grau de empregabilidade" é o conjunto de competências que ele é capaz de construir. A respeito deste aspecto, Deluiz (2001) aponta que:

Os elementos das novas práticas de gestão que configuram o modelo da 
competência no mundo do trabalho são a valorização dos altos níveis de escolaridade nas normas de contratação; a valorização da mobilidade e do acompanhamento individualizado da carreira: novos critérios de avaliação que valorizam as competências relativas à organização dos trabalhadores (...) A adoção do modelo das competências profissionais pelas gerências de recursos humanos no mundo empresarial está relacionada ao uso, controle, formação e avaliação do desempenho da força de trabalho diante das novas exigências postas pelo padrão de acumulação capitalista flexível ou toyotista: competitividade, produtividade, agilidade, racionalização de custos. Este modelo tende a se tornar hegemônico em um quadro de crise no trabalho assalariado e da organização prescrita do trabalhador e do declínio das organizações profissionais e políticas dos trabalhadores (DELUIZ, 2001, p. 14, Grifos nossos)

Neste sentido, diante de um mercado globalizado e exigente, a formação de um novo tipo de trabalhador, que dê conta de todos os atributos valorizados pelo mundo do trabalho, passa ser cada vez mais necessária e abrangente. Com base na atual estruturação do mercado de trabalho, considerando ainda os dados apresentados sobre o lento impacto da escolarização na diminuição das desigualdades sociais e a expansão do ensino superior por meio de instituições privadas de ensino, a adjetivação "popular" acaba por conferir ao ensino superior um caráter excludente. Recria-se a marca da exclusão a partir do momento em que se mantém um determinado padrão que não mais se encaixa na nova ordem do capital globalizado.

As classes populares correm para o arco-íris, mas o pote de ouro já mudou de lugar.

\section{Referências}

ALGEBAILE, Maria Emilia B, NASCIMENTO, Alexandre do, SILVA, Andréia Ferreira da. Estado, mercado e trabalho: neoliberalismo e políticas sociais. In: NEVES, Lúcia(Org.). O empresariamento da educação: novos contornos do ensino superior no Brasil dos anos 1990.

BRANDÃO, Carlos Rodrigues. Soletrar a letra P: povo, popular, partido e política. In: FÀVERO, Osmar e SEMERARO, Giovanni (Orgs.). Democracia e construção do público no pensamento educacional brasileiro. Petrópolis: Vozes. 2002. p. 105-145.

BRASIL. MARE. Plano Diretor da Reforma do Aparelho do Estado. Brasília, 1995. 
BOITO Jr., Armando. Política neoliberal e sindicalismo no Brasil. São Paulo, SP: Xamã, 1999.

CATANI, Afrânio Mendes, OLIVEIRA, João Ferreira de, DOURADO, Luiz Fernandes. Política educacional, mudanças no mundo do trabalho e reforma curricular dos cursos de graduação no Brasil. Educação \& Sociedade: revista quadrimestral de Ciência da Educação (CEDES), Campinas, n. 75, p. 67-83, 2001.

COGGIOLA, Osvaldo; HELENE, Otaviano. Seqüência ou inconseqüência? Folha de São Paulo, São Paulo, SP.13 jul. 2002.

DELUIZ, Neise. O modelo das competências profissionais no mundo do trabalho e na educação: implicações para o currículo. Boletim Técnico do SENAC, Rio de Janeiro, v. 27, n. 3, p. 17-25.set./dez. 2001.

GADOTTI, Moacyr. FME - Educação ambiental: dentro ou fora da escola? Entrevista com Moacyr Gadotti. Disponível em: http://www.rebea.org.br/ entrevista moacyr.htm. Acesso em 10 mar. 2003.

JORNAL Extra Classe. Entrevista com Carlos Rodrigues Brandão. Em busca da escola cidadã. Outubro de 2002. Disponível em: http://www.sinpro-rs.org.br/ extra/out02/educacao.asp Acesso em 10 mar. 2003.

LIMA, Kátia Regina de Souza. Organismos internacionais: o capital em busca de novos campos de exploração. In: NEVES, Lúcia (Org.). O empresariamento da educação: novos contornos do ensino superior no Brasil dos anos 1990. São Paulo, SP: Xamã, 2002.

NEVES, Lúcia (Org.). O empresariamento da educação: novos contornos do ensino superior no Brasil dos anos 1990. São Paulo: Xamã, 2002.

SILVA, Tomás Tadeu da. Teoria cultural e educação: um vocabulário crítico. Belo Horizonte: Autêntica, 2000. 